\title{
O ENSINO DE MATEMÁTICA NA EDUCAÇÃO INFANTIL NA PERSPECTIVA DA TEORIA HISTÓRICO-CULTURAL
}

\author{
THE TEACHING OF MATHEMATICS IN CHILDREN EDUCATION IN THE \\ PERSPECTIVE OF THE HISTORICAL-CULTURAL THEORY
}

\author{
Gesraeli de Souza Machado ${ }^{1}$ \\ Eloir Fátima Mondardo Cardoso ${ }^{2}$ \\ Daiane de Freitas ${ }^{3}$
}

RESUMO: A escolha do tema deste trabalho é decorrente das reflexões sobre o ensino de Matemática na proposição davidoviana, na disciplina Processos Pedagógicos de Matemática. O primeiro contato com este ensino causou resistência por parte das acadêmicas. Tal fato levou a refletir sobre o desenvolvimento da proposição davidoviana desde a Educação Infantil. A pesquisa se define como qualitativa, direcionada pelo problema: quais elaborações conceituais da grandeza comprimento os estudantes da Educação Infantil manifestam quando o ensino é organizado com base em uma situação desencadeadora de aprendizagem? A partir do problema, definem-se os objetivos: analisar as elaborações conceituais da grandeza comprimento pelos estudantes da Educação Infantil e reconhecer o que caracteriza as elaborações dos estudantes pesquisados. Para tanto, procede-se o estudo das grandezas conforme a proposição davidoviana, segundo interpretação de Rosa (2012) e da Atividade Orientadora de Ensino de Moura (1996). O conteúdo para análise foi obtido a partir do desenvolvimento da situação desencadeadora "O presente de Cristal" em uma turma da Educaçao Infantil com crianças de 4 a 5 anos em uma Escola da Rede Municipal de Criciúma - SC. Davydov (1982) propõe o ensino de modo a promover o desenvolvimento do pensamento teórico e, para isso, se deve colocar a criança em constante ação investigativa desde a primeira infância. $\mathrm{Na}$ análise da situação desencadeadora de aprendizagem, as crianças manifestaram compreensão da linguagem matemática relativa à identificação dos comprimentos das caixas. Além disso, as manifestações das crianças, em momento algum, foram de resistência como ocorreu com a turma do Curso de Pedagogia.

PALAVRAS-CHAVE: Proposição Davidoviana. Situação desencadeadora de aprendizagem. Grandeza comprimento. Educação Infantil.

ABSTRACT: The choice of this work's theme derives from the reflections on the teaching of Mathematics in the Davidovian's proposition, during the classes of the subject Pedagogical Processes of Mathematics. In the first contact with this theory, in the classroom, there was resistance among the academics, this fact led to reflect on the development of Davidovian's proposition since Childhood Education. This research is defined as qualitative and has as its

\footnotetext{
${ }^{1}$ Graduada em Pedagogia - UNESC.rlb@unesc.net

${ }^{2}$ Graduada em Matemática - Mestre em Educação/UNESC. efm@unesc.net

${ }^{3}$ Graduada em Matemática - rlb@unesc.net

Saberes Pedagógicos, Criciúma, v. 3, nº1, janeiro/junho 2019.- Curso de Pedagogia- UNESC
} 


\section{SABERES PEDAGÓGICOS}

Revista do Curso de Graduaçāo de Pedagogia - Unesc

ISSN 2526-4559
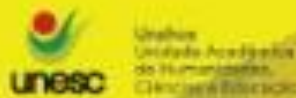

SWe

research question: which conceptual elaborations of length greatness do preschool students manifest when teaching is organized based on a triggering learning situation? From the research question, the objectives were defined: to analyze the conceptual elaborations of the greatness length by the preschool students and to recognize what characterizes the elaborations of the researched students. Therefore, was proceeded to study the greatness according to the Davidovian's proposition, based on the interpretation of Rosa (2012) and Moura's work Atividade Orientadora de Ensino (1996). The corpus for analysis was obtained from the development of the triggering situation "O presente de Cristal" in a preschool class with children from 4 to 5 years old at a school of the municipal educational system of Criciúma - SC. Davydov proposes teaching in order to promote the development of theoretical thinking and, for this, the child needs to be constantly encouraged to develop investigative actions from an early age. In the analysis of the situation triggering learning, the children expressed an understanding of the mathematical language regarding the identification of the lengths of the boxes. Moreover, the children's reaction, at any moment, were of "resistance" as it happened with the college students.

KEYWORDS: Davidovian's preposition. Situation triggering learning. Greatness length. Childhood Education.

\section{INTRODUÇÃO}

A escolha do tema “O Ensino da Matemática na Educação Infantil na Perspectiva da Teoria Histórico-cultural" emergiu durante a disciplina Processos Pedagógicos da Matemática, na quinta fase do Curso de Licenciatura em Pedagogia (UNESC), no primeiro semestre de 2016. Nas aulas da referida disciplina, refletiu-se sobre o ensino de Matemática, no Ensino Fundamental (EF) anos iniciais, numa perspectiva davidoviana com base nos seguintes autores: Rosa (2012), Rosa, Damazio e Crestani (2014), Freitas (2016), entre outros.

Vale destacar que o primeiro contato com o estudo davidoviano causou, a mim e às demais acadêmicas, alguma resistência. Nossa expectativa era a reprodução do ensino de Matemática ao qual estávamos acostumadas, aquele oriundo da formação obtida durante toda a escolarização na Educação Básica. No entanto, a professora nos desafiou a analisar alguns livros didáticos brasileiros de Matemática, os mais usados por professores do primeiro ao quinto ano, da região de Criciúma - SC. O objetivo desta análise era estabelecer as principais diferenças entre o modo de organização do ensino de Matemática em duas proposições: a dos livros didáticos brasileiros e a de Davídov e seus colaboradores. 
As discussões sobre o Ensino Desenvolvimental, mesmo se tratando de algo novo, possibilitaram nos evidenciar alguns indícios e características que diferem ambas as proposições, citadas anteriormente. Por exemplo, o ensino de Matemática proposto nos livros didáticos brasileiros dá ênfase apenas para as experiências vividas no dia a dia e na observação direta dos objetos concretos de forma visual, ou seja, base para o desenvolvimento do pensamento empírico. Por outro lado, Davídov ${ }^{4}$ propõe o ensino de modo a promover o desenvolvimento do pensamento teórico. A proposição davidoviana está organizada de modo a possibilitar, às crianças, o desenvolvimento de análises mediante a transformação dos dados do objeto estudado. Por isso, busca, no processo de ensino, colocar as crianças em constante ação investigativa.

Diante do exposto e da trajetória acadêmico foi que surgiu a necessidade de se abordar o presente tema de pesquisa para o desenvolvimento do Trabalho de Conclusão de Curso (TCC). Tal tema gerou a reflexão sobre o desenvolvimento da proposição davidoviana desde a Educação Infantil. Considera-se relevante o objeto do estudo desta pesquisa uma vez que dentre os TCC's e artigos produzidos no Curso de Pedagogia da UNESC não consta nenhum trabalho referente à proposição de ensino davidoviana na Educação Infantil. Desse modo, se trata de um tema inédito. No entanto, dada a diversidade de conceitos matemáticos na Educação Infantil e as limitações deste trabalho, optou-se pela grandeza comprimento. A escolha não é aleatória, uma vez que as grandezas (comprimento, área, volume entre outras), na proposição davidoviana, expressam o geral para o ensino de todo conceito matemático.

Tais evidências se constituíram como base para a definição do problema central desta pesquisa na seguinte questão: quais elaborações conceituais da grandeza comprimento os estudantes da Educação Infantil manifestam quando o ensino é organizado com base em uma situação desencadeadora de aprendizagem? Ponderou-se que esta pergunta não garante a reflexão do problema definido. Sendo assim, considerou-se relevante a elaboração de outros questionamentos: a) Que situação desencadeadora promoveria as elaborações da grandeza comprimento pelos estudantes da Educação Infantil? b) $\mathrm{O}$ que caracterizam as elaborações

\footnotetext{
4 Vasili Vasilievich Davydov nasceu em 1930 e morreu em 1998. Membro da Academia de Ciências Pedagógicas, doutor em Psicologia e professor universitário. Autor de várias obras sobre o Ensino Desenvolvimental (LIBÂNEO E FREITAS, 2013). No decorrer do texto será utilizada a grafia Davídov. Porém, Saberes Pedagógicos, Criciúma, v. 3, n²1, janeiro/junho 2019.- Curso de Pedagogia- UNESC
} 

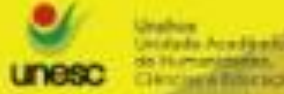

destes estudantes? A partir das questões, elencaram-se como objetivos específicos: analisar as elaborações conceituais da grandeza comprimento pelos estudantes da Educação Infantil e reconhecer o que caracterizam as elaborações dos estudantes pesquisados.

Salienta-se que, além da proposição davidoviana, a Atividade Orientadora de Ensino, desenvolvida pelo professor Manoel Oriosvaldo de Moura $^{5}$ (1996) nos fundamentou teoricamente para a elaboração e desenvolvimento da situação desencadeadora de aprendizagem "O presente de Cristal”, em uma turma da Educação Infantil com crianças de 4 a 5 anos em uma instituição de ensino da Rede pública do município de Criciúma - SC.

\section{A MATEMÁTICA NA EDUCAÇÃO INFANTIL: UM ESTUDO DA GRANDEZA COMPRIMENTO NA PERSPECTIVA DAVIDOVIANA}

Para compreender o tema Educação Infantil, iniciaram-se os estudos a partir das seguintes reflexões: a criança é um ser de escolhas, desejos e vontades? Ela se constitui em um sujeito sociocultural, com direitos e deveres? Em busca das possíveis respostas a essas indagações, subsidiamo-nos na Proposta Curricular Nacional para a Educação Infantil, na qual “A criança como todo ser humano, é um sujeito social e histórico e faz parte de uma organização familiar que está inserida em uma sociedade, com uma determinada cultura, em um determinado momento histórico [...]" (BRASIL, 1998, p. 21). Isso porque, de acordo com Leontiev (2004, p. 291) "O movimento da história só é, portanto, possível com a transmissão, às novas gerações, das aquisições da cultura humana, isto é, com educação. ”.

Por certo, há que se considerar que cada criança está inserida em uma família específica, com apropriações diferentes em relação à cultura, à educação, à religião, entre outros aspectos. Vigotski (2000, p. 21), diz que: Uma das premissas histórico-cultural e de que a criança, enquanto inserida no seio familiar, apresenta o desenvolvimento do seu pensamento e a consequente percepção do mundo com características do senso comum e fundamentos no empirismo. Contudo, vale destacar que, ao frequentar a escola, a criança se

ao se tratar de referencia, sera mantida a escrita conforme apresentada na obra referenciada, quais sejam: Davídov, Davidov, Davýdov.

${ }^{5}$ É professor titular da faculdade de educação da USP-FEUSP. Sua área de atuação é a Educação Matemática, com foco em metodologia do ensino de Matemática, formação de professores e teoria da atividade.

Saberes Pedagógicos, Criciúma, v. 3, nº1, janeiro/junho 2019.- Curso de Pedagogia- UNESC 

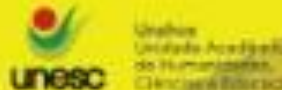

unese

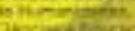

depara com novas formas de conhecimento, cuja complexidade exige uma organização que promova a superação dos conceitos até então apropriados por elas. Pois, conforme Davídov (1988), a aquisição de novos conceitos sistematizados permite que haja o desenvolvimento do pensamento dos estudantes para além das situações cotidianas.

Nesta perspectiva, entende-se que é responsabilidade da escola promover, na criança, o pensamento teórico por meio da apropriação dos conceitos científicos. Davídov (1988) diz que o pensamento empírico obstaculiza o desenvolvimento do pensamento teórico. Desse modo, a apropriação de conhecimentos científicos, desde a primeira infância, implicará no desenvolvimento integral da criança.

Nesse sentido, reafirmamos que Davídov, citado por Rosa (2012, p. 37), evidencia e dá ênfase "[...] ao papel da educação e do ensino no desenvolvimento intelectual do homem". Porém, Davídov (1987-1988 apud ROSA; MORAES; CEDRO 2010 A, p.71) “[...] critica a escola tradicional, dominada pelo método intuitivo, em que o trabalho com os conhecimentos e as habilidades reside na dimensão utilitária e empírica, própria da prática cotidiana das pessoas".

Morais (1988) diz que o senso comum, ou "conhecimento vulgar", pode ser designado como "empírico", e que "provém da experiência comum das gentes". O conhecimento sem bases científicas e sem fundamentos teóricos são apenas experiências passadas de um para o outro. Cotrim (2002, p. 46) contribui com este pensamento quando diz que o "[...] vasto conjunto de concepções geralmente aceitas como verdadeiras em determinado meio social recebe o nome de senso comum".

Davídov e seus colaboradores não consideram o conhecimento empírico como ponto de partida para o desenvolvimento do pensamento. Em outras palavras, deve-se levar em consideração no processo de pensamento a apreensão dos conceitos científicos, a fim de desenvolver o pensamento teórico. Este, por sua vez, “[...] trata-se de um procedimento especial com que o homem enfoca a compreensão das coisas e os acontecimentos por via da análise e das condições de sua origem e desenvolvimento". (DAVÍDOV, 1998 apud FREITAS, 2016, p. 63)

Vale ressaltar que o desenvolvimento do pensamento por via da análise, de acordo com Davídov (1988), é possibilitado mediante a organização do ensino, de modo a criar a

Saberes Pedagógicos, Criciúma, v. 3, nº1, janeiro/junho 2019.- Curso de Pedagogia- UNESC 

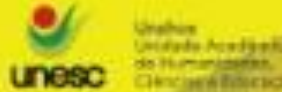

necessidade da atividade de estudo por parte das crianças. Tal atividade deverá ser organizada com a finalidade de direcionar o movimento do pensamento dos estudantes para a apropriação da lógica conceitual e das leis de formação dos conceitos. Vygotsky (2000, p. 226) explica que "[...] o conceito surge quando uma série de atributos abstraídos torna a sintetizar-se, e quando a síntese abstrata assim obtida se torna forma basilar de pensamento”. Com base nisso é que a criança percebe e toma conhecimento da realidade circundante.

Davídov (1988, p. 72) diz que ter se apropriado de um conceito consiste em reproduzir mentalmente o conteúdo de um objeto, sendo que "[...] a ação mental de sua construção e transformação constitui o ato de sua compreensão e explicação, o descobrimento de sua essência".

Para Peres e Freitas $(2014$, p. 15) “[...] a criança nasce com a potencialidade de aprender, com aptidão de aprender, enfim, com capacidade ilimitada de aprendizagem", Sendo assim, cabe ao professor, na ação pedagógica, criar situações de aprendizagem que possa desenvolver tais capacidades. Entretanto, pressupõe-se que, para trabalhar o conhecimento teórico na Educação Infantil, é preciso organizar o ensino tal como Davídov propõe para os anos iniciais, isto é, colocando as crianças em constante ação investigativa.

Segundo Davídov (1988, p. 93) “[...] a base do Ensino Desenvolvimental é o seu conteúdo e dele se originam os métodos de organização de ensino". Assim, é de responsabilidade do professor o conhecimento do conceito teórico para propiciar aos alunos tarefas de teor científico, e que os alunos se utilizem de ferramentas mentais para a resolução das tarefas organizadas pelo professor.

Além disso, vale destacar que as tarefas, na proposição davidoviana de ensino, estão organizadas de modo a colocar a criança em ação investigativa, a fim de elevar o pensamento do plano objetal ao plano mental. Moura et al (2010, p. 216 b) contribuem quando dizem que o professor deve "[...] criar, no estudante, a necessidade do conceito, fazendo coincidir os motivos da atividade com o objetivo de estudo".

Nesse sentido, em consonância com Davídov, quando afirma que cabe à escola organizar um ensino que conduza a aprendizagem e ao desenvolvimento das crianças, Moura (1996) desenvolve a Atividade Orientadora de Ensino a partir dos fundamentos da Teoria Histórico-Cultural e da Teoria da Atividade, com o propósito de contribuir com o 
desenvolvimento do pensamento teórico dos estudantes desde a Educação Infantil. Damazio et al (2012, p.182) dizem que “[...] não é qualquer modo de ensinar tão pouco qualquer conteúdo, que podem promover o desenvolvimento humano, mas aqueles que intencionalmente forem organizados para esse fim”. Matos (2017, p. 99) postula que Moura, “[...] no contexto da Atividade Orientadora de Ensino, propõe situações desencadeadoras de aprendizagem, que ocorrem por meio de diferentes recursos metodológicos: jogos infantis, história virtual do objeto de ensino e situações emergentes do cotidiano".

Neste âmbito, vale salientar que, de acordo com o problema desta pesquisa, que objetiva investigar as elaborações conceituais da grandeza comprimento por estudantes da pré-escola, o recurso metodológico é o desenvolvimento da situação desencadeadora de aprendizagem emergente do cotidiano, intitulada "O presente de Cristal”.

Segundo Rosa $(2012$, p.85) “[...] as grandezas se constituem em elemento central do processo de formação do pensamento teórico de matemática”. Desse modo, pressupõe-se que uma situação emergente do cotidiano, como a história "O presente de Cristal", para a Educação Infantil, possibilitará que as crianças não alfabetizadas se apropriem do conhecimento teórico de grandeza.

Damazio et al (2012, p. 181) afirmam que "A criança tem o contato com a matemática desde o nascimento, pois interage cotidianamente com grandezas diversas e objetos, produções humanas, materiais ou ideias, com características peculiares”. Desse modo, dado o objeto de estudo desta pesquisa, considera-se relevante apresentarmos uma síntese das tarefas de introdução da grandeza comprimento, tal como Davídov e seus colaboradores propõem, conforme interpretação de Rosa (2012).

\subsection{CONCEITO DE GRANDEZA}

A primeira grandeza contemplada na proposição davidoviana é o comprimento. Por este motivo, o comprimento é o ponto de partida do estudo das grandezas em Davídov (ROSA, 2012).

A criança procura, nos objetos, a característica para destacar o parâmetro de comparação. Inicialmente, as características qualitativas (cor, forma, tamanho e posição) e, 
posteriormente, as quantitativas (comprimento, área, volume, capacidade, massa, entre outras). Davydov (1982) considera que a base de todo conhecimento humano é a práticaobjetal. De modo a explicitar tais características é que se expõem as tarefas a seguir.

Tarefa 1: O professor apresenta às crianças o desenho de uma casa com um pilar faltando. São apresentadas algumas possibilidades de pilares, diferentes pela cor, pela forma, para que os alunos escolham, convenientemente, aquele que falta, conforme figura 1 ГОРБОВ, МИКУЛИНА е САВЕЛЬЕВА (2008 apud ROSА 2012):

Figura 1: Casa inacabada

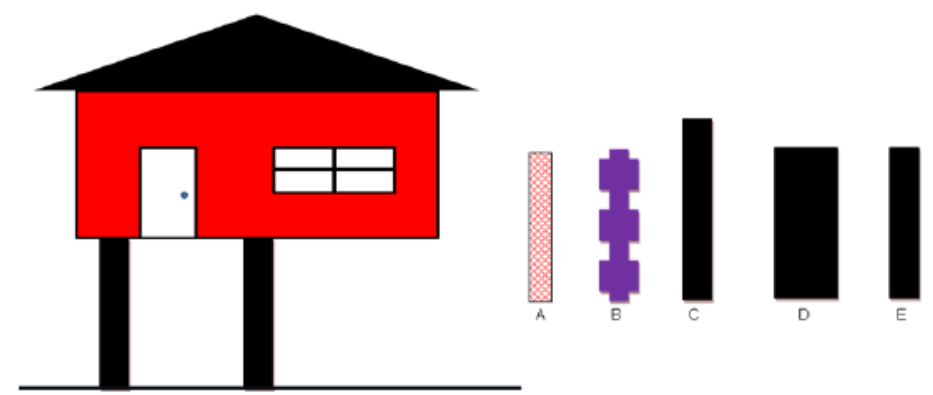

Fonte: ROSA (2012, p. 71)

Se as crianças escolherem a figura $\mathrm{E}$ antes das outras, o professor precisa instigálas a investigar as outras figuras e questionar. Por exemplo, é só pela cor que a figura A não se encaixa? Pelo tamanho podemos colocar a figura C? Existe outra possibilidade pelo tamanho? Qual tamanho? As reflexões sobre as possibilidades inadequadas instigam a ação investigativa, pelas crianças, das características em análise, além da observação direta dada unicamente pela imagem.

Tarefa 2: As crianças desenham no caderno uma linha reta, com o uso da régua (Figura 2). O professor pede para marcarem dois pontos nesta reta e destacar a parte que une estes pontos com lápis de outra cor. O professor fala que a parte destacada se chama segmento, às vezes, os pontos, inicial e final do segmento são marcados com os riscos, como se fossem a linha de corte.

Figura 2: Segmento de reta

Saberes Pedagógicos, Criciúma, v. 3, nº1, janeiro/junho 2019.- Curso de Pedagogia- UNESC 

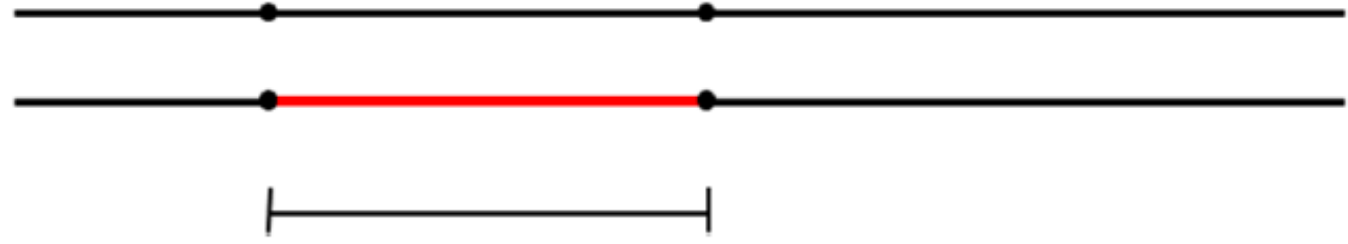

Fonte: ROSA (2012, p. 89)

Segundo Rosa (2012, p. 89)

O diálogo entre professor e as crianças deverá contemplar as seguintes questões: Qual tipo de linha foi desenhada? O quanto ela pode ser estendida? Ela tem fim ou não? Tais questionamentos tornam-se referência para a reflexão sobre a diferença entre o segmento e linha reta e, também, para elaborar a conclusão de que a linha reta não tem fim, pela possibilidade de continuá-la ilimitadamente. Por sua vez, o segmento é uma parte dela e tem suas extremidades definidas.

Davídov introduz a intersecção entre linhas para a compreensão da ideia de ponto no contexto da matemática, pelas crianças. (DAMAZIO, CARDOSO E SANTOS,2014, p. 7).

Tarefa 3: Para que as crianças identifiquem a primeira especificação da ideia de tamanho, qual seja a grandeza comprimento, coloca-se à disposição das crianças objetos, um ao lado do outro (ROSA, 2012). A análise leva a concluir que um objeto tem vários comprimentos: a largura, a altura e a espessura.

É retomada a tarefa da casa inacabada, porém, a análise é para o tamanho do comprimento da altura e da largura do pilar. Outra tarefa consiste em disponibilizar recortes de papel de superfícies retangulares, conforme Figura 3. Primeiramente, faz-se um acordo sobre qual comprimento será considerado (ГОРБОВ, МИКУЛИНА е САВЕЛЬЕВА, 2008 apud ROSA 2012).

Figura 3: Comparação grandeza comprimento com recortes de papel

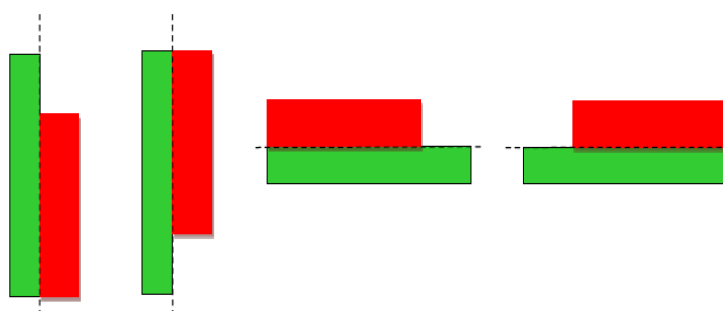

Fonte: ROSA (2012, p. 92)

Saberes Pedagógicos, Criciúma, v. 3, nº1, janeiro/junho 2019.- Curso de Pedagogia- UNESC 
Rosa (2012, p. 92) complementa que, "essa tarefa tem o objetivo de trazer para a criança tanto a noção dos modos de comparação do comprimento, quanto da linguagem adequada, por exemplo, percebe-se que o comprimento do recorte verde é maior que o comprimento do recorte vermelho".

Tarefa 4: Nesta tarefa, o foco é acrescentar o modo de comparação do tamanho da grandeza área pela sobreposição das figuras. Esta grandeza difere-se do modo de comparação do comprimento, trata-se da superfície da figura denominada plana. É proposta a comparação de dois recortes, pela área, pelo comprimento da altura e pelo comprimento da largura. Em cada caso, exige-se atenção ao modo correto de comparação que requer a colocação um ao lado do outro, quando o foco é comprimento e um sobre o outro, no caso da área (figura 4).

Figura 4: Comparação grandeza comprimento e área com recortes de papel
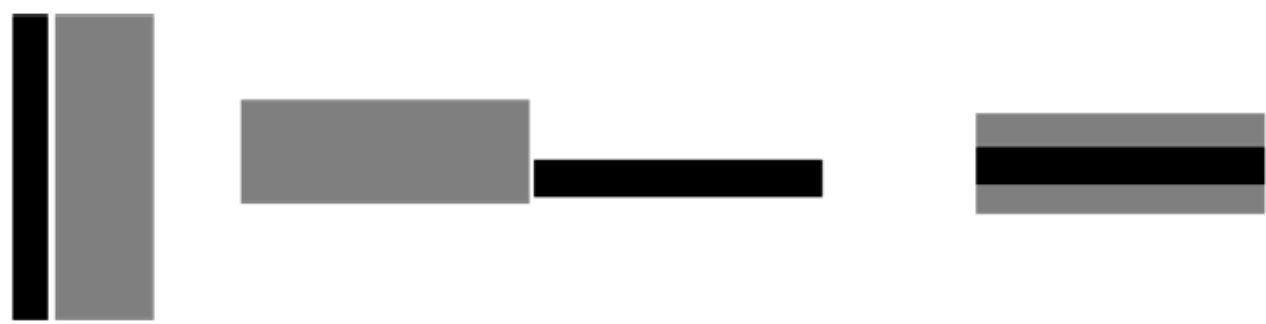

Fonte: ROSA (2012, p. 102)

Na Figura 4, o primeiro caso representa a comparação pela largura, o segundo pela altura e o terceiro, concomitantemente, pela área, pela largura e pela altura.

Tarefa 5: O volume é outro parâmetro da ideia de tamanho. O professor apresenta duas caixas, em forma de paralelepípedo, em que uma caiba dentro da outra. As crianças devem compará-las e, dependendo da posição, a mesma caixa pode ser mais alta ou mais baixa que a outra. No caso das faces, a área pode ter ou não ter a mesma medida, pois depende se, ao serem sobrepostas, as superfícies coincidem ou não. (ГОРБОВ, МИКУЛИНА е САВЕЛЬЕВА, 2008 apud ROSA, 2012).

Saberes Pedagógicos, Criciúma, v. 3, nº1, janeiro/junho 2019.- Curso de Pedagogia- UNESC 


\section{SABERES PEDAGÓGICOS}

Revista do Curso de Graduaçāo de Pedagogia - Unesc

ISSN 2526-4559

Figura 5: Comparação das grandezas comprimento, área e volume
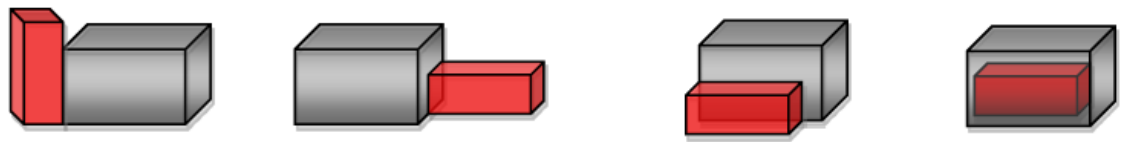

Fonte: ROSA (2012, p. 106)

O procedimento de comparação, no qual o professor deve orientar as crianças, é, na sua totalidade, pelo comprimento da altura, da largura, da espessura/profundidade e, assim, inserir uma caixa dentro da outra. Desse modo, aquela inserida totalmente é a menor. A maior terá sobra de espaço em seu interior. Nesse caso, podemos concluir que a menor caixa (que coube inteiramente na outra) possui um volume (capacidade) menor em relação àquela que teve sobra de espaço.

Tarefa 6: Nesta tarefa, cada criança recebe três tiras iguais na cor e no comprimento da largura, duas delas têm o mesmo comprimento da altura e a terceira é mais curta. O professor mostra duas figuras para que os estudantes as comparem, conforme todas as características estudadas, e elaborem, em silêncio, suas conclusões. Por exemplo, se a propriedade comparada for a forma e elas forem iguais, as crianças mostram tiras iguais, caso contrário, se forem desiguais, mostram duas tiras diferentes, conforme Figura 6 (ГОРБОВ,
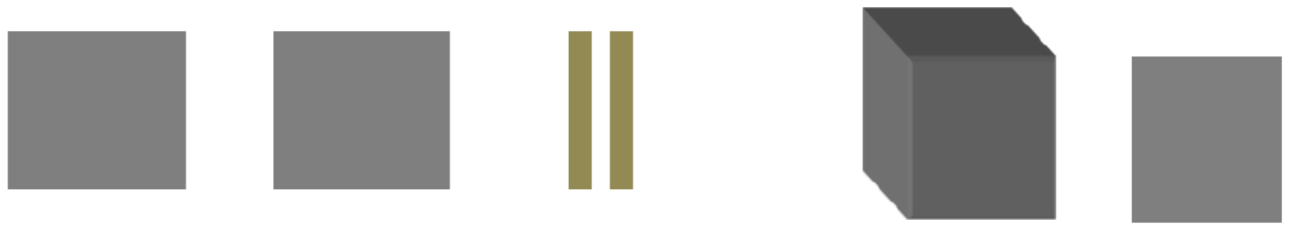

МИКУЛИНА е САВЕЛЬЕВА, 2008 apud ROSA 2012).

Figura 6: Representação de igualdade e desigualdade com tiras de papel Fonte: ROSA (2012, p. 105)

As tiras de papel, representação objetal, indicam a igualdade ou desigualdade, na análise das características dos objetos e figuras.

Saberes Pedagógicos, Criciúma, v. 3, nº1, janeiro/junho 2019.- Curso de Pedagogia- UNESC 

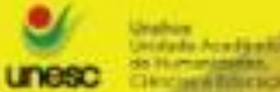

Nesse contexto de estudo foi que se desencadeou o debate sobre a grandeza comprimento, considerada ponto de partida na elaboração da história "O presente de Cristal", conforme segue:

\section{O presente de Cristal}

Era uma vez duas amigas inseparáveis, Cristal e Julia, amigas que se gostavam muito. Elas brincavam sempre juntas, no entanto, elas adoravam ler livros. Passavam as tardes lendo debaixo do pé de laranjeira no quintal da dona Benta, uma boa velhinha do bairro, que adorava crianças.

O dia da festa do aniversário de Julia se aproximava, ela convidou todas as crianças do bairro, inclusive Cristal, sua melhor amiga. Na semana que antecedia o dia da festa de Julia, Cristal foi ao centro escolher um presente para a amiga. Pensou, pensou, procurou, procurou e exclamou entusiasmada - Já sei! O presente que Julia irá adorar será um livro.

Logo, era preciso encontrar um livro que tivesse significado para as amigas. Ao passar por uma livraria, viu na vitrine o livro "MELHORES AMIGAS PARA SEMPRE". Não teve dúvida - é este que vou comprar. - Disse emocionada. Estava tão satisfeita com o presente, que foi logo para casa guardá-lo, antes que Julia a encontrasse com o presente. Não queria estragar a surpresa.

Ao chegar em casa, Cristal se deu conta de que havia esquecido de comprar uma caixa para colocar o livro. Sua mãe havia deixado um bilhete avisando que iria ao supermercado, rapidamente pegou o telefone e ligou para sua mãe. Assim que a mãe de Cristal atendeu ao telefone, Cristal disse - Mamãe! Mamãe! A senhora ainda está no supermercado?

Sua mãe responde - Calma menina! Sim, estou, o que aconteceu?

Cristal respira aliviada e diz - Ufa! Ainda bem, preciso que a senhora compre uma caixa de presente, para eu colocar o livro que comprei para Julia.

Sua mãe diz - Tudo bem filha, pode deixar que eu compro, beijo. 
No supermercado, a mãe de Cristal encontrou uma grande quantidade de caixas, de cores, de tamanhos e de estampas diferentes. Eram tantas as opções que resolveu levar duas, para que Cristal escolhesse a mais linda.

Em casa, entregou as duas caixas para Cristal. Lá foi Cristal toda entusiasmada colocar o livro na caixa. Ao colocar o livro na primeira caixa, tentou de todas as formas e o livro não coube. Pegou a outra caixa e, aí sim, coube certinho, como se fosse feita para aquele livro. A sorte que a mãe de Cristal comprou duas caixas, não é mesmo? Mas, Cristal não conseguia entender, as caixas pareciam ser do mesmo tamanho. Por que o livro não coube na primeira caixa?

\section{METODOLOGIA, APRESENTAÇÃO E ANÁLISE DE DADOS}

O trabalho de pesquisa em questão tem como objetivo principal desenvolver o ensino da grandeza comprimento na perspectiva da Atividade Orientadora de Aprendizagem de Moura (1996) e do Ensino Desenvolvimental de Davídov (1988), na Educação Infantil. Além de analisar o desenvolvimento da situação desencadeadora de aprendizagem " $\mathrm{O}$ presente de Cristal", em uma turma da Educação Infantil.

A proposta foi realizada em uma turma mista com 23 alunos de 4 a 5 anos durante uma tarde, previamente agendada com a professora regente, em uma escola municipal da cidade de Criciúma - SC.

A coleta de dados para análise foi realizada por meio de filmagens, fotos e diário de bordo realizado pela pesquisadora e professora regente. A utilização dos dados e imagens dos sujeitos da pesquisa foi autorizada pela diretora da escola, mediante assinatura do termo de consentimento.

A modalidade da pesquisa é qualitativa de natureza básica, cujos dados coletados foram analisados profundamente pela pesquisadora, não dando espaço para quantificação. Além disso, visa compreender as manifestações e as apropriações das crianças durante o desenvolvimento da situação desencadeadora de aprendizagem. De acordo com Rauen (2015, p.531) "Numa pesquisa de caráter qualitativo, há de se considerar um vínculo dinâmico entre 

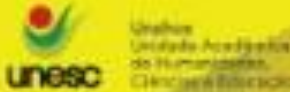

sujeitos e realidade que não se traduz em números ou estatísticas, mas a partir da interpretação e da atribuição processual e indutivamente descritiva de significados".

A seguir, apresentaremos a análise dos dados coletados, na vivência realizada na sala de aula a partir da história "O presente de Cristal". Para preservar a identidade dos sujeitos da pesquisa, identificaremos suas falas pela letra $\mathrm{C}$, acompanhada por um número sobreposto aleatoriamente, de 1 a 6 . E, para identificar a fala da pesquisadora, utilizou-se a letra P.

\subsection{ANÁLISE DAS MANIFESTAÇÕES DAS CRIANÇAS NO DESENVOLVIMENTO DA SITUAÇÃO DESENCADEADORA DE APRENDIZAGEM "O PRESENTE DE CRISTAL"}

Como dito anteriormente, o problema da presente pesquisa consiste em investigar as elaborações conceituais da grandeza comprimento por estudantes da Educação Infantil quando o ensino é organizado com base em uma situação desencadeadora de aprendizagem. Para isso, o ponto de partida foi a contação da história "O presente de Cristal", desenvolvida pela pesquisadora com base em Matos (2017), Rosa (2012) e Flores (2015). Segundo Moura (2001, p. 155) a Atividade Orientadora de Ensino "[...] se estrutura de modo a permitir que os sujeitos interajam, mediados por um conteúdo negociando significados, com o objetivo de solucionar coletivamente uma situação-problema".

As crianças foram organizadas lado a lado, em um círculo, para que a pesquisadora pudesse perceber e analisar as manifestações de todas as crianças e, também, para envolvê-las na investigação inerente à história. Assim, colocá-las em investigação é dar asas à imaginação, de modo que a ludicidade ultrapasse as ações puramente empíricas. Rosa (2012, p. 70) diz que se deve "[...] inicialmente, colocar a criança em ação investigativa, que contribuirá para desenvolver-lhe a capacidade de estruturar autonomamente e transformar de modo criador sua própria atividade de estudo".

A concentração foi unânime e, ao final, questionei-as, repetindo a pergunta do final da história.

P: A sorte é que a mãe de Cristal comprou duas caixas, não é mesmo?

Saberes Pedagógicos, Criciúma, v. 3, nº1, janeiro/junho 2019.- Curso de Pedagogia- UNESC 

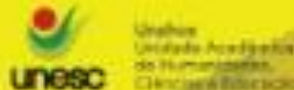

unesc

ancintions

C: Se a mãe dela comprasse só a que não cabia ia ter que levar sem colocar na caixa de presente.

P: Por que o livro não coube na primeira caixa?

$\mathrm{C}^{3}$ : Porque a caixa era "mais pequena" que o livro.

Os indícios aparentes na resposta de $\mathrm{C}^{3}$ não são suficientes para inferirmos que a compreensão sobre a grandeza comprimento do estudante, foco deste estudo, se aproxima do que Davídov denomina de conhecimento teórico.

Desse modo, solicitei que cada criança fosse escolher duas caixas, dentre as várias que estavam sobre uma mesa. As caixas eram diferentes pelo tamanho e pela cor, mas iguais pela forma. Elas tinham que escolher duas caixas em que uma delas era a que a mãe de Cristal havia comprado.

Na concepção davidoviana, propõe-se a comparação de objetos semelhantes com a finalidade de destacar as relações de igualdade e desigualdade. Rosa (2012, p. 132) diz que o "[...] princípio interno de igualdade e desigualdade entre as grandezas é reconstruído, sob a forma de conceito teórico, na tarefa desenvolvida coletivamente pelas crianças e o professor, que a dirige".

As crianças realizaram a comparação, inicialmente, por tentativas, inserindo o livro nas caixas até que conseguissem introduzi-lo totalmente. Não tínhamos, neste momento, a intenção de desconsiderar tal procedimento, mas levar a criança a superar o pensamento empírico dado, unicamente, na prática sensorial. Segundo Davýdov (1982, p. 316):

\footnotetext{
Tipos especiais de atividade sensorial, a contemplação viva, são capazes de refletir a conexão universal, isto é, podem cumprir a função de pensamento teórico, mas refletem ainda uma forma não dissociada, pois esse pensamento aparece em sua 'simplicidade primitiva', ainda não se desenvolveu, não obteve verdadeira soberania.
}

Após várias tentativas, uma das crianças exclamou - Esta é a caixa! Mostrando aquela em que o livro coube completamente em seu interior, mas com sobra de espaço.

P: Esta é a caixa, pessoal?

$C^{3}$ : Não, porque na história disse que ficou certinho, e essa aí sobrou muito espaço.

Saberes Pedagógicos, Criciúma, v. 3, nº1, janeiro/junho 2019.- Curso de Pedagogia- UNESC 
$\mathrm{C}^{2}$ : Mas o livro coube.

P: Por que sobrou espaço na caixa?

$\mathrm{C}^{2}$ : Porque o livro é menor que a caixa, entendeu!?

$\mathrm{O}$ envolvimento das crianças, durante a investigação, foi unânime; todas experimentaram as várias possibilidades de comparações com as caixas e o livro. Ao encontrar a caixa certa, ou seja, aquela em que o livro coube perfeitamente, todos vibraram e disseram “É essa! Essa é a caixa, né, professora?".

A experimentação objetal, segundo Davýdov (1982), é o início do desenvolvimento do pensamento teórico, ainda em sua fase primitiva. Rosa (2012, p.50), em conformidade com Davídov, diz que "[...] durante a reprodução do objeto em forma de conhecimento teórico, o pensamento sai dos limites das representações sensoriais, se fixa na conexão entre a relação geral e suas manifestações particulares”. Portanto, faz se necessário estabelecer relações entre o imediato, dado pela observação direta, visão e tato e a conexão interna da grandeza comprimento em análise, pela comparação. Rosa (2012, p.60) afirma também que "[...] mesmo antes de se apropriar do conceito de número, a criança consegue determinar os resultados da comparação, com a ajuda de fórmulas literais tais como: $a=b, a>$ b, a $<$ b.".

Desse modo, a comparação que resultou na igualdade entre as dimensões comprimento da largura, comprimento da altura e comprimento da profundidade/espessura da caixa e do livro possibilita compreender o motivo pelo qual o livro coube exatamente na caixa, além da experimentação sensorial.

No diálogo com as crianças, em relação aos diversos comprimentos dos objetos (três dimensões), definimos o comprimento da altura, da largura e da profundidade/espessura, conforme a Figura abaixo:

Figura 7: Representação geométrica tridimensional

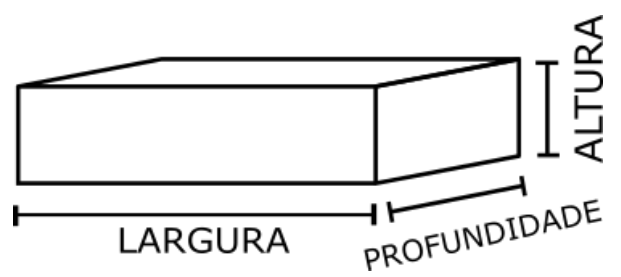

Fonte: da autora

Saberes Pedagógicos, Criciúma, v. 3, n¹, janeiro/junho 2019.- Curso de Pedagogia- UNESC 
Tais relações propiciaram, no processo da ação investigativa, um diálogo entre a pesquisadora e as crianças, que revelaram algumas manifestações representadas por $\mathrm{C}^{5}$ e $\mathrm{C}^{4}$.

P: Onde fica o comprimento da altura dessa caixa?

$\mathrm{C}^{5}$ : Aqui no cantinho igual a outra, prof $^{\mathrm{a}}$.

$\mathrm{C}^{4}$ : É porque altura é o que vai pra cima.

Davýdov (1982) afirma que “[...] é papel da educação escolar oferecer as condições para a efetiva apropriação dos conhecimentos científicos pelos estudantes, por meio de reflexões teóricas".

$\mathrm{Na}$ sequência, a ideia de comparação dos tamanhos das dimensões tem continuidade com a representação da igualdade e desigualdade por meio de tiras de papel, primeiro passo para atingir o conceito abstrato de grandeza. As respostas das crianças, em relação à comparação dos comprimentos das caixas, eram dadas em silêncio. A pesquisadora aproximava lado a lado, por exemplo, os comprimentos da largura de duas caixas, as crianças mostravam duas tiras iguais se os tamanhos eram iguais e, se eram desiguais, duas tiras de tamanhos diferentes. Os comprimentos de outros objetos da sala de aula, como a altura da cadeira da professora em relação às cadeiras dos alunos, o comprimento da altura de um colega em relação ao outro, foram analisados pelas crianças e a igualdade ou a desigualdade expressa por meio das tiras.

Na sequência, as crianças assumiram o papel da pesquisadora, se dirigiram ao centro do círculo e questionavam os colegas sobre os comprimentos de uma caixa em relação à outra, cujas respostas eram manifestadas por meio da representação objetal com as tiras de papel.

Figura 8: Comparação da largura, altura e profundidade das caixas. 


\section{SABERES PEDAGÓGICOS}

Revista do Curso de Graduaçāo de Pedagogia - Unesc

ISSN 2526-4559

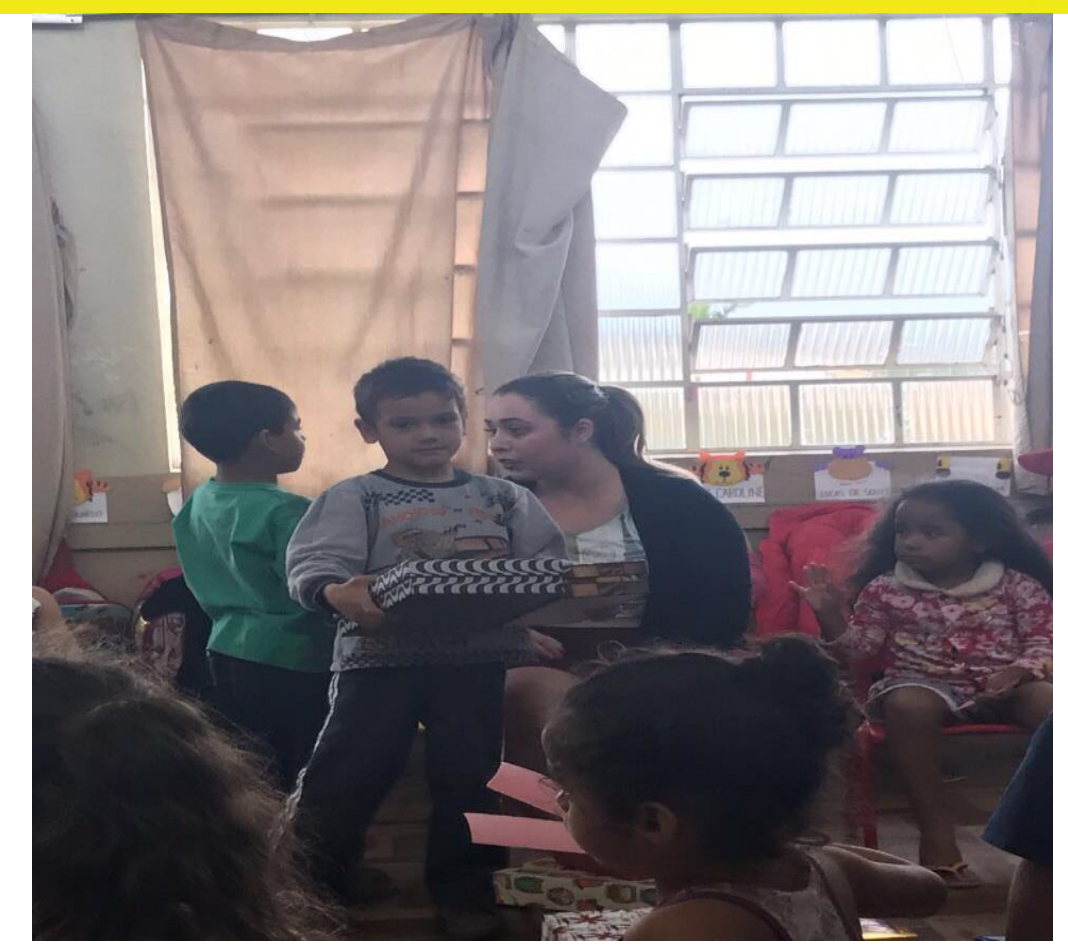

Fonte: Acervo da pesquisadora

Ao término do desenvolvimento da situação desencadeadora de aprendizagem da grandeza comprimento, pôde-se concluir que as manifestações das crianças, em momento algum, foram de "resistência", como ocorreu com a turma do curso de Pedagogia, conforme dito na introdução deste trabalho. Pressupõe-se que essa resistência ocorre devido ao conhecimento fossilizado constituído pelo ensino tradicional durante a formação acadêmica. Desse modo, considera-se que a ação pedagógica possibilitou reflexões e discussões teóricas com crianças da pré-escola e que estimularam falas como as que seguem:

C6: Foi muito legal aprender os comprimentos das coisas.

C5: Por exemplo, a prof ${ }^{\mathrm{a}}$ tem o comprimento de altura maior que o meu comprimento de altura.

$\mathrm{C}^{2}$ Prof $^{\mathrm{a}}$, nós queremos fazer uma carta para você, sobre a história.

Figura 9: Obra de arte representação da história de Cristal, desenvolvida por Ana Clara, 2017 


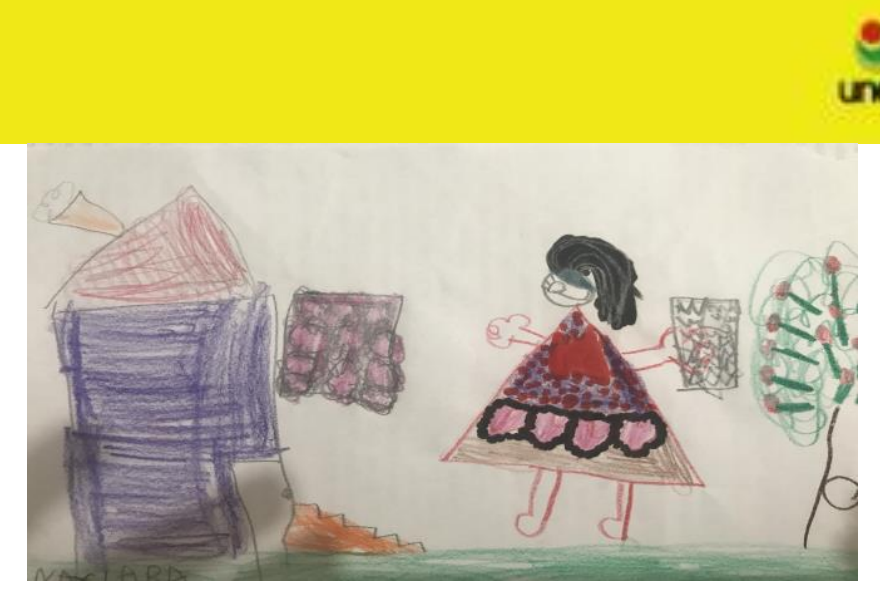

Fonte: Acervo da pesquisadora

Assim, o encerramento da aula se deu com a produção de desenhos sobre a história "O presente de Cristal", conforme figura 9.

\section{CONSIDERAÇÕES FINAIS}

Como dito na introdução deste trabalho, o interesse por esta pesquisa e a definição do objeto de estudo surgiram na quinta fase do curso de Pedagogia (Unesc). A proposição de ensino de Davídov, apresentada pela professora da disciplina Processos Pedagógicos de Matemática, causou expectativa e resistência por parte das acadêmicas. No entanto, instigou o interesse em desenvolver uma experiência de ensino com uma turma da Educação Infantil. A escolha do objeto de estudo foi devido à escassa produção de pesquisa com esta faixa etária. Nesse âmbito, direcionou-se o olhar da investigação para responder a seguinte questão que se constituiu como problema central da pesquisa: quais elaborações conceituais da grandeza comprimento os estudantes da Educação Infantil manifestam quando o ensino é organizado com base em uma situação desencadeadora de aprendizagem? Para responder o questionamento, estudou-se a literatura relacionada ao Ensino Desenvolvimental, a Atividade Orientadora de Ensino e as grandezas comprimento, área e volume.

Nesta perspectiva, para análise e coleta dos dados, a pesquisadora contou para as crianças, de uma turma da Educação Infantil de 4 e 5 anos, a história intitulada "O Presente de Cristal". A história levava as crianças a refletirem sobre a razão pela qual o livro não coube em uma das caixas, entre duas opções aparentemente de mesmo tamanho. 
$\mathrm{Na}$ organização e desenvolvimento da ação pedagógica, evidenciou-se que, no modo davidoviano de organização de ensino de Matemática, o foco é a relação entre grandezas. Ou seja, a grandeza é a base geral de todo conceito matemático e, se desenvolvido adequadamente, desenvolve o pensamento teórico das crianças, inclusive na Educação Infantil.

Desse modo, conclui-se que a situação desencadeadora de aprendizagem possibilitou colocar as crianças em ação investigativa de modo a desenvolverem, mesmo que em suas noções iniciais, o pensamento teórico, no que se refere à compreensão da grandeza comprimento. Tais indícios se evidenciaram na linguagem das crianças, por exemplo, na fala de uma delas ao comparar o comprimento da sua altura com o comprimento da altura da pesquisadora. Além disso, reitera-se que as crianças, em momento algum, foram resistentes, pelo contrário, se mantiveram concentradas e participaram efetivamente durante toda a ação pedagógica. Assim, é possível dizer que a resistência das acadêmicas da turma do curso de Pedagogia é devida ao conhecimento cristalizado constituído durante toda a formação acadêmica, desenvolvida pelo ensino tradicional.

Enfim, considera-se que os resultados obtidos na referida turma da Educação Infantil indicam que a proposição de ensino de Davídov é uma possibilidade para o desenvolvimento do pensamento teórico das crianças. No entanto, manifesta-se a necessidade de continuidade e proposição, por outros pesquisadores desta área, de novas ações pedagógicas com crianças da Educação Infantil.

\section{REFERÊNCIAS}

BRASIL. Ministério da Educação e do Desporto, Secretaria de Educação Fundamental. Referencial curricular nacional para a Educação Infantil. Brasília: MEC/SEF, 1998. 3v.: il.

COTRIM. Gilberto. Fundamentos da filosofia: história e grandes temas. 15. ed. São Paulo: Saraiva, 2002. 


\section{SABERES PEDAGÓGICOS}

Revista do Curso de Graduaçāo de Pedagogia - Unesc

ISSN $2526-4559$

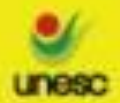

DAMAZIO, Ademir et al. Conhecimento matemático na Educação Infantil. In

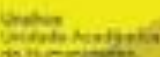

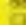

Dalânea C; DURLI, Zenilde (Org.). Educação Infantil e formação de professores.

: FLÕR,

Florianopolis: Ed. da UFSC, 2012, p. 179-192.

DAMAZIO, Ademir; CARDOSO, Eloir Fátima Mondardo; SANTOS, Felipe Everaldo dos. Organização do ensino da matemática no sistema de ensino Elkonin-Davídov. Revista

Electrónica de Investigación y Docencia (REID), 11, Enero, 2014, p. 179-198.

DAVÝDOV, V.V. Tipos de generalización en la enseñanza. 3. ed. Habana: Editorial Pueblo y Educación, 1982.

DAVÍDOV. La enseñanza escolar y el desarrollo psíquico: investigación teórica y experimental. Trad. Marta Shuare. Moscú: Editorial Progreso, 1988.

FREITAS, Daiane De. O movimento do pensamento expresso nas tarefas particulares proposta por Davydov e colaboradores para apropriação do sistema conceitual de fração. Dissertação de Mestrado em educação da Universidade do Extremo Sul Catarinense, 2016.

LEONTIEV, A. N. O desenvolvimento do psiquismo. São Paulo: Centauro, 2004.

LIBÂNEO, J. C.; FREITAS, R. A. M. M. Vasily Vasilyevich Davydov: A escola e a formação do pensamento teórico- científico. In: LONGAREZI, A. M.; PUENTES, R. V. (Orgs.). O Ensino desenvolvimental: vida, pensamento e obra dos principais representantes russos. Uberlândia: EDUFU, 2013. p. 315- 350.

MATOS, Cristina Felipe de. Modo de organização do ensino da matemática em cursos de pedagogia: uma reflexão a partir dos fundamentos da teoria histórico-cultural. Dissertação de Mestrado em Educação da Universidade do Sul de Santa Catarina, 2017.

MELLO, Suely A. A escola de Vygotsky. In : CARRARA, Kester (Org.). Introdução à psicologia da educação: seis abordagens. São Paulo: Avercamp, 2004.

MORAIS, Regis de. Filosofia da ciência e da tecnologia. 5. ed. São Paulo: Papirus, 1988.

MOURA, Manoel Orisvaldo de; et al. A atividade orientadora de ensino como unidade entre ensino e aprendizagem. In : MOURA, Manoel Orisvaldo de. (Org.). A atividade pedagógica na teoria histórico-cultural. Brasília: Liber livro, 2010, p. 81-94.

MOURA, M. O. et al.: unidade entre ensino e aprendizagem. Revista Diálogo Educacional, Curitiba, v. 10, n. 29, p. 205-229, jan./abr. 2010.

A atividade de ensino como unidade formadora. Bolema, Rio Claro, UNESP, v. 12, p. 29-43, 1996. 
A atividade de ensino como ação formadora. In : CASTRO, A.; CARVALHO, A (Orgs.). Ensinar a ensinar: didática para a escola. São Paulo: Editora Pioneira, 2001. p. 143-161.

PERES, Thalitta de Carvalho; FREITAS, Raquel Aparecida Marra da Madeira. Ensino desenvolvimental: Uma alternativa para a educação matemática. Poiésis: Tubarão. Volume especial, p. 10-28, jan/jun, 2014.

ROSA, Josélia Euzébio da; FLORES, Monica Medeiros. O movimento conceitual da tabuada na história virtual Luer e seu foguete. Rev. Teoria e Pratica da Educação, v. 18, n.2, p. 55-68, Maio/Agosto 2015.

ROSA, Josélia Euzébio da; MORAES, Silvia Pereira Gonzaga de; CEDRO, Wellington Lima. As particularidades do pensamento empírico e do pensamento teórico na organização de ensino. In : MOURA, Manoel Oriosvaldo de. (Org.). A atividade pedagógica na teoria histórico-cultural. Brasília: Liber livro, 2010, p. 67-76.

ROSA, Josélia Euzébio da; Proposições de Davydov para o ensino da matemática no primeiro ano escolar: inter-relações dos sistemas de significações numéricas. Tese (Doutorado em Educação). Universidade Federal do Paraná, Curitiba, 2012.

ROSENTAL, M. M.; STRAKS, G. M. Categorías del Materialismo Dialéctico. Tradução de Adolfo Sanchez Vazquez e Wenceslao Roces. México: Grijalbo, 1958.

VIGOTSKI, L.S. A construção do pensamento e da linguagem. Tradução de Bezerra P. São Paulo: Martins Fontes, 2000. 